\title{
Study of Interactive Development Model of Producer Services and Manufacturing Industry Based on Symbiotic Theory
}

\author{
Bohui Pang \\ Dongwu Business School, Soochow University, Suzhou, China \\ Email address: \\ bhpang@suda.edu.cn
}

\section{To cite this article:}

Bohui Pang. Study of Interactive Development Model of Producer Services and Manufacturing Industry Based on Symbiotic Theory. International Journal of Economics, Finance and Management Sciences. Vol. 4, No. 5, 2016, pp. 292-297. doi: 10.11648/j.ijefm.20160405.19

Received: August 22, 2016; Accepted: September 23, 2016; Published: October 13, 2016

\begin{abstract}
Although the relationship between producer services and manufacturing industry has become the focus, the related theoretical problem has been little investigated. From the perspective of symbiosis theory, this paper analyzes the interactive development model of producer services and manufacturing, and analyzes respectively the symbiosis organization mode and symbiotic behavior mode. The two symbiosis units exist eight symbiotic modes, and the characteristics of each symbiotic mode are given. In addition, the interaction stages of production service industry and manufacturing industry are divided into 4 stages, which include the infancy stage, growth stage, maturity stage and integration stage.
\end{abstract}

Keywords: Producer Services, Manufacturing Industry, Symbiotic Mode, Interaction Stage

\section{Introduction}

In China, the service industry developed rapidly with the transformation of economic strategy. This growth performance of services for the production expansion and quality improvement around the "strong industry" is launched [1]. The 13th Five-Years planning proposal has pointed out that the government should speed up the development of modern service industry, promote productive and professional services to extend the value chain, push the manufacturing sector for production services, and improve the overall competitiveness and added-value of the manufacturing sector. Obviously. For a long period in future, the symbiotic development of producer services and manufacturing will be the best mode of industrial structure adjustment evolution in China. In this background, the study about symbiotic relationship between the producer services and manufacturing has become a hot topic.

In recent years, some scholars studied the relationship between producer services and manufacturing from the perspective of symbiotic interaction, and the symbiosis nature of producer services and manufacturing is proposed. $\mathrm{Du}$ Zhuying (2007) applied the Logistic model to demonstrate the behavior pattern of symbiotic relationship between manufacturing and producer services with the selection mechanism [2]. Nie $\mathrm{Na}$ (2007) analyzed the formation and evolution condition of the symbiotic relationship between the logistics enterprises and manufacturers based on symbiosis theory [3]. Xu Xuejun (2008) discussed the organization models between producer services and manufacturing by applying the symbiotic media and interface and built the empirical symbiotic model of producer services and manufacturing [4]. HU Xiaopeng and Li Qingke (2009) analyzed the present situation of service industries of Jiangsu, Zhejiang and Shanghai in China and gave the basic features and symbiotic evaluation about the producer services and manufacturing [5]. Liu Hao and Yuan Yijun (2013) studied the symbiotic behavior patterns and regional differences based on the total factor productivity and quality parameter panel data of the producer services and manufacturing in China [6]. Liu Junyue (2013) evaluated the 31 provinces symbiotic relationship between producer services and manufacturing industry by using the coupling coordination degree of symbiotic evaluation model [7]. Miao Lindong (2014) measured the basic characteristics of the symbiotic relationship between the producer services and manufacturing of Yangtze River Delta, Pearl River Delta and the Bohai Rim Region in China [8]. 
This paper will focus on the fundamental and theoretical research of the symbiotic relationship perspective between produce services and manufacturing, propose the overall pattern of symbiotic development between producer services and manufacturing by analyzing the organization symbiotic mode and behavior symbiotic mode, divide the development stage of interactive and symbiosis mode for producer services and manufacturing, and give the corresponding mode and its specific performance characteristics at each stage.

\section{Symbiotic Interactive Mode of Producer Services and Manufacturing}

Symbiotic interactive mode of producer services and manufacturing refers to the interaction way of two symbiotic units between producer services and manufacturing. Symbiotic mode is determined by the symbiotic unit and the symbiotic environment, and varies with the change of symbiotic environment and unit. The symbiotic system includes the symbiotic organization mode and the symbiotic behavior mode. The symbiotic organization mode reflects the symbiotic interaction among the organization units, which is divided by the link frequency, action mode, the stability degree and evolutionary features. The organization mode includes point symbiosis, batch symbiosis, continuous symbiosis and integration symbiosis. The symbiotic behavior mode reflects the interaction way of the benefits distribution and behavior category among symbiotic units, which includes parasitic symbiosis, partial symbiosis, asymmetric mutualism symbiosis and symmetric mutualism symbiosis. A large number of new business are generated under the effect of symbiotic behavior mode in the field of producer services and manufacturing. The symbiotic organization mode contributes to the growth of a large number of manufacturing enterprises and producer services enterprises, and makes the symbiotic interaction of produce services and manufacturing from the initial stages to mature stage gradually.

\subsection{Symbiotic Organization Mode of Produce Services and Manufacturing}

From the perspective of the symbiotic organization mode, the point symbiosis, intermittent symbiosis, continuous symbiosis and integration symbiosis reflect the extent of the symbiotic unit from low to high. Point symbiosis reflects the link process of symbiotic unit and the occasional transactions between producer services and manufacturing. The symbiotic process is randomness, uncertainty, short-term and instability. Therefore, point symbiotic mode produces limited energy to promote the symbiotic units evolution of producer services and manufacturing. However, the point symbiotic mode is the first phase of symbiotic unit evolution and is budding stage and the initial stage.

Intermittent symbiosis reflects the link process of symbiotic unit transactions between producer services and manufacturing, including regular intermittent symbiosis and irregular intermittent symbiosis. Compared with point symbiotic mode, intermittent symbiotic mode is still uncertain and unstable despite the randomness characteristics is reduced significantly. Continuous symbiosis is a continuous transaction process among the symbiosis unit. Compared with continuous and intermittent symbiosis, continuous symbiotic mode reflects a long-term stability and continuous connection among symbiotic unit and is the inevitable choice for enterprise development. Symbiotic unit will obtain the maximum benefit in such a stable link, and maintain their independence at the same time. Symbiosis companies will forward the continuous development of the symbiotic relationship.

Integration symbiosis can be considered as an extreme form of continuous symbiosis, external symbiotic unit evolves into the interior symbiotic relationship. The different symbiotic companies have become a combination of nature and structure of the independent symbiont. In the integration symbiosis mode, the independence of original independent enterprises disappear, the original interests relationship among enterprises have been replaced by the authority relationship, and turned into bureaucratic hierarchical organization. The stability of integration symbiosis has disappeared when its independence is weaken. The new energy generated by symbiosis unit will gradually be counteracted when the management costs in bureaucratic hierarchical organization increases up to a certain range.

\subsection{Symbiotic Behavior Mode of Producer Services and Manufacturing}

Symbiosis behavior mode of producer services and manufacturing includes parasitic symbiosis, partial symbiosis, asymmetric mutualism symbiosis and symmetric mutualism symbiosis. Parasitic symbiotic process among enterprises can be considered as the process that one party company incubators another company. And partial symbiosis is a process that one enterprise incubates another company. Mutualism symbiosis is the process that enterprises both sides cooperate equally. Mutualism symbiotic behavior of producer services and manufacturing is dominated. Parasitic symbiosis is a special mode, which does not generate new energy, but changes the energy distribution of the host. There is only a one-way flow of energy and matter in a parasitic relationship that flows parasite from the host, the host is the energy producer, but parasite is energy consumer. In the market economy, companies pursue economic interests, some companies can not maintain a long-term nonprofit relationship. Parasitic symbiotic relationship exists universally in the biosphere, but the parasitic symbiotic system exists only in the early stages when producer services has not been separated out from manufacturing.

Partial benefit symbiotic behavior pattern is the transition from the parasitic symbiotic mutualism mode. Partial benefit symbiotic relationship will generate new energy, but the energy is only transferred to the new symbiotic relationship, the dominant symbiotic unit will obtain all the new energy. Because the partial benefit symbiotic behavior pattern can only achieve a single win and is short of enthusiasm, a link 
economic conditions are hard to maintain. Therefore, the partial benefit symbiosis pattern in the symbiotic system of producer services and manufacturing will exist, but is difficult to maintain their long-term and stable symbiotic relationship.

Mutualism symbiosis can be further subdivided into asymmetric and symmetric mutualism symbiosis, which generates new energy and is the main behavior mode among symbiotic unit of producer services and manufacturing. It is possible to achieve a win-win situation and persistent characteristics. Asymmetry mutualism symbiosis is based on the division of mutualism symbiotic unit. Due to the role of the symbiotic interface, the new generated energy exhibits asymmetric distribution, and the bidirectional exchange of matter, energy and information exists. The new value generated by the enterprises of asymmetry mutualism symbiosis reflects the value division of symbiotic activity, which is related to the properties and functions of the symbiotic interface. Asymmetry mutualism symbiosis effects the characteristics of symbiosis unit in the following two aspects. Firstly, the division and cooperation result in bilateral and multilateral mechanisms. The symbiosis unit will occur qualitative change in the multilateral mechanism, gradually expand the scope, and improve the efficiency. And the symbiosis loss gradually reduces, but the symbiosis value increases. Secondly the asymmetry symbiosis makes a difference for the amount of value-added, which leads to asynchronous evolutionary among different companies and declines the symbiosis stability. The stability of asymmetric mutualism symbiosis is decided by two factors. One is the non-symmetry of the extent and scope, the other one is the nature and function of the symbiotic interface. The lower the degree of asymmetry is, the smaller the range is and the better the symbiotic stability is.

Symmetry mutualism symbiosis is the most ideal development mode among the symbiosis modes, which owns the maximum efficiency, the strongest cohesion, and the reliable stability. But symmetry mutualism symbiosis is very rare in the actual symbiosis unit of producer services and manufacturing. Symmetry mutualism symbiosis is based on division and cooperation and generate the new value with more efficient activities. The symmetry of distribution among symbiotic enterprises is realized, each company have access to the symbiotic evolutionary development, and the survivability of symbiotic companies is improved. Symbiotic companies will get the same evolution, and form a new symbiotic relationship. Through the above analysis, a long stability and evolution can be obtained if each symbiotic units can get benefits from the symbiotic system.

\section{Selection of Symbiotic Interaction Mode Between Producer Services and Manufacturing}

By analyzing symbiotic organization mode and symbiotic behavior mode between producer services and manufacturing, there are eight major symbiosis modes, as shown in table 1.

Table 1. Symbiotic interaction mode between producer services and manufacturing.

\begin{tabular}{|c|c|c|c|c|c|}
\hline & $\begin{array}{l}\text { Parasitic } \\
\text { symbiosis }\end{array}$ & partial symbiosis & $\begin{array}{l}\text { Asymmetric } \\
\text { mutualism symbiosis }\end{array}$ & $\begin{array}{l}\text { Symmetric mutualism } \\
\text { symbiosis }\end{array}$ & Performance of organization \\
\hline Point symbiosis & $\begin{array}{l}\text { Point \& parasitic } \\
\text { symbiosis }\end{array}$ & $\begin{array}{l}\text { Point \& partial } \\
\text { symbiosis }\end{array}$ & N/A & N/A & $\begin{array}{l}\text { Symbiosis is randomness, uncertainty, } \\
\text { short-term and unstable and is the } \\
\text { fundamental and initial stage. }\end{array}$ \\
\hline Batch symbiosis & $\begin{array}{l}\text { Batch \& parasitic } \\
\text { symbiosis }\end{array}$ & $\begin{array}{l}\text { Batch \& partial } \\
\text { symbiosis }\end{array}$ & $\begin{array}{l}\text { Batch \& asymmetric } \\
\text { mutualism symbiosis }\end{array}$ & N/A & $\begin{array}{l}\text { Symbiotic process belongs to the } \\
\text { uncertain and unstable, the symbiotic } \\
\text { relationship among company units is } \\
\text { discontinuous. }\end{array}$ \\
\hline Continuous symbiosis & N/A & N/A & $\begin{array}{l}\text { Continuous \& } \\
\text { asymmetric mutualism } \\
\text { symbiosis }\end{array}$ & $\begin{array}{l}\text { Continuous \& symmetric } \\
\text { mutualism symbiosis }\end{array}$ & $\begin{array}{l}\text { Symbiotic unit forms a long-term, } \\
\text { continuous and stable relationship, each } \\
\text { company is independent. }\end{array}$ \\
\hline Integration symbiosis & N/A & 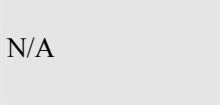 & N/A & $\begin{array}{l}\text { Integration \& symmetric } \\
\text { mutualism symbiosis }\end{array}$ & $\begin{array}{l}\text { Independence of each company is } \\
\text { disappear and symbiotic efficiency is } \\
\text { lower. }\end{array}$ \\
\hline $\begin{array}{l}\text { Performance of } \\
\text { behavior mode }\end{array}$ & $\begin{array}{l}\text { One-way energy } \\
\text { flow and no new } \\
\text { energy generation }\end{array}$ & $\begin{array}{l}\text { Two-way matter } \\
\text { and energy flow, } \\
\text { generally partial } \\
\text { one party, and the } \\
\text { total energy } \\
\text { increases. }\end{array}$ & $\begin{array}{l}\text { Based on the division } \\
\text { and generate new energy } \\
\text { to the uneven } \\
\text { distribution of energy }\end{array}$ & $\begin{array}{l}\text { Based on division and } \\
\text { cooperation, generate new } \\
\text { energy, new energy } \\
\text { distribution more evenly. }\end{array}$ & \\
\hline
\end{tabular}

This parasitic behavior in symbiotic unit of producer services and manufacturing symbiosis exists only in the initial budding stage, and producer services has not been separated from manufacturing. This parasitic behavior includes point symbiosis or intermittent symbiosis. Integration symbiotic relationship must be reciprocal symmetry, and the integration $\&$ symmetric mutualism symbiosis is the only symbiotic mode. Partial symbiosis and intermittent symbiosis occasionally appear. Asymmetric symbiotic mutualism mainly occurs in continuous and intermittent symbiotic relationship. Continuous \& symmetric mutualism symbiosis is the most representative of the producer services and manufacturing symbiosis mode, which generates new energy, makes companies get respective interests in the symbiotic system, and maintains independence respectively with the strongest stability. 
By analyzing of symbiotic behavior and organization symbiosis mode of producer services and manufacturing, the life cycle is illustrated in figure 1 during the symbiosis development of the producer services and manufacturing. In the initial budding stage of producer services and manufacturing, symbiotic companies begin to gradually establish a symbiotic relationship, generally producer services parasites in the manufacturing sector. The main symbiosis modes includes point $\&$ parasitic symbiosis, point $\&$ partial symbiosis, batch \& parasitic symbiosis, batch \& partial symbiosis, batch \& asymmetric mutualism symbiosis and continuous \& asymmetric mutualism symbiosis, and then gradually evolves to continuous and asymmetric mutualism symbiosis. In the growth stage of the producer services and manufacturing, symbiotic interface among enterprises gradually expands and symbiosis mode includes batch \& asymmetric mutualism symbiosis, continuous \& asymmetric mutualism symbiosis and continuous \& symmetric mutualism symbiosis. In this stage, producer services and manufacturing develop rapidly. In the mature stage, the symbiotic interface among enterprises is also more diverse, the symbiosis relationship includes continuous \& symmetric mutualism symbiosis, integration \& symmetric mutualism symbiosis, which forms a more stable symbiotic relationship. In the integration stage, the integration \& symmetric mutualism symbiosis is the only symmetric mode.

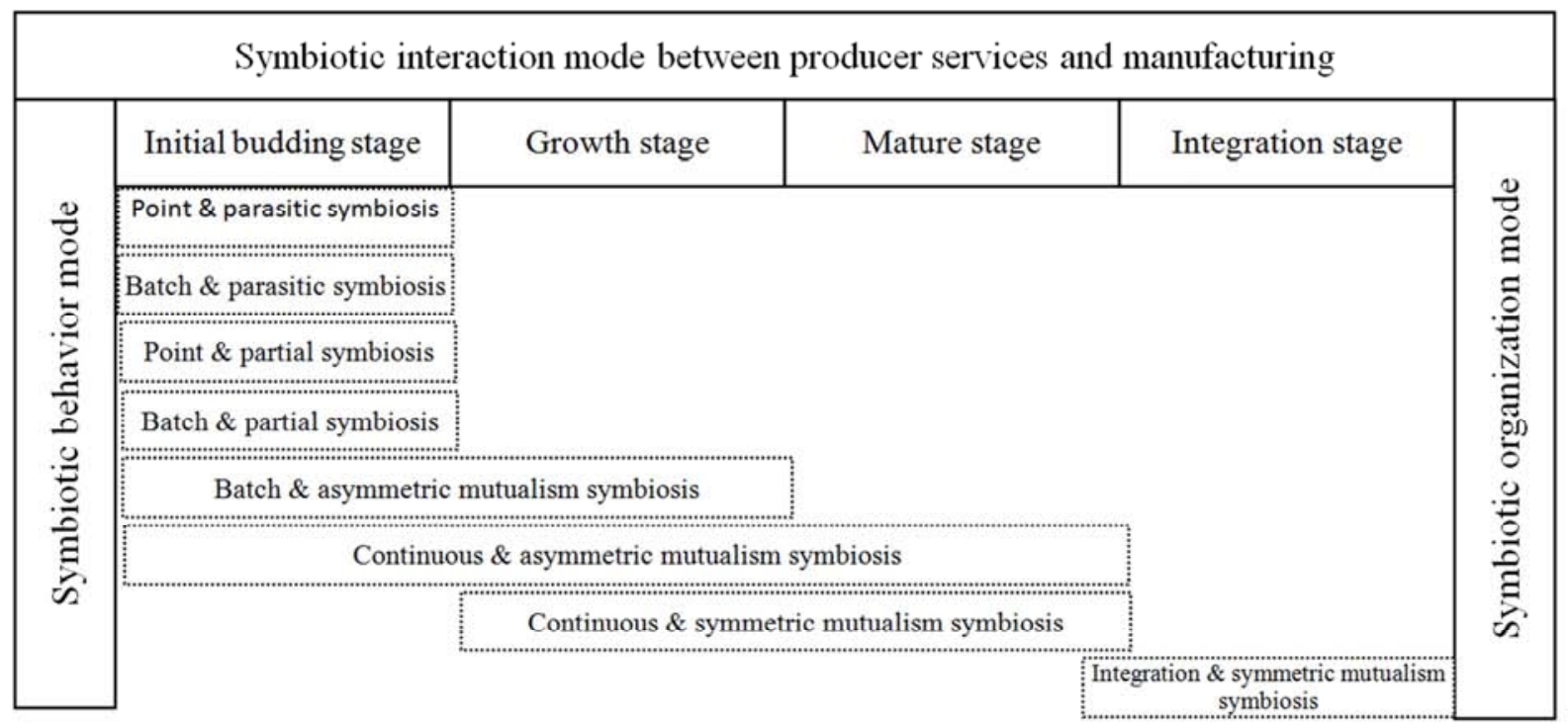

Figure 1. Selection of symbiotic interaction mode between producer services and manufacturing.

\section{Development Stage Division of Symbiosis Mode Between Producer Services and Manufacturing}

Development of symbiosis unit of producer services and manufacturing is a continuous process. From the perspective of the ecology, the number of producer services and manufacturing population are constrained by the resources, systems and technology, and need to go through development from childhood to adulthood which is the same as the ecological system in nature. Based on symbiotic evolution Logistic model, this article will analyze dynamic evolution process of the producer services and manufacturing [9]. The Logistic equation can be expressed as follows:

$$
\left\{\begin{array}{l}
\frac{d N(t)}{d t}=r\left[1-\frac{N(t)}{N_{m}}\right] N(t) \\
N\left(t_{0}\right)=N_{0}
\end{array}\right.
$$

Where $N(t)$ is population density in year $t ; r$ is the natural growth rate of population; $t_{0}$ is the equation initial value and the value is equal to $0 ; N_{0}$ is maximum environmental capacity under the initial conditions; $N_{m}$ is allowed maximum environmental capacity by the Natural Resources and Environment. Logistic equation of the curve is shown in figure 2 .

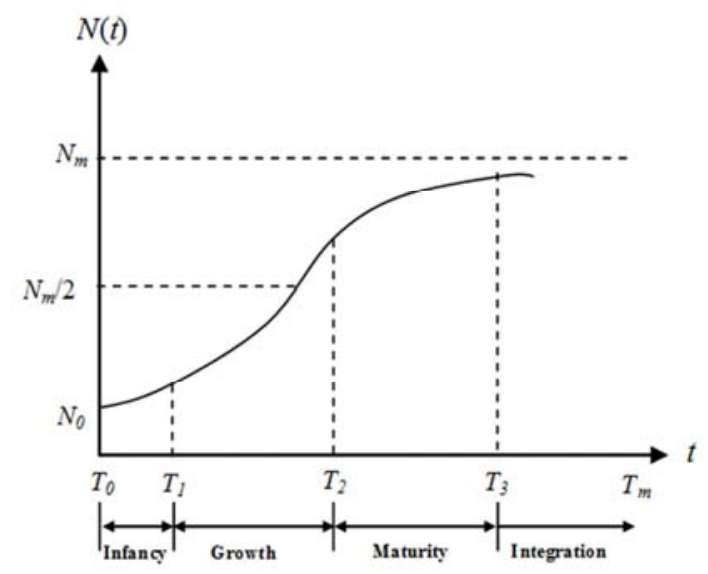

Figure 2. Logistic curve and division of development stage.

Development of producer services and manufacturing can be divided into four stages which are infancy, growth, 
maturity and integration period which are shown in figure 1 . Although there are many factors determining the development phase of producer services and manufacturing, this paper uses the ratio of population density $N$ and maximum environmental capacity $N_{m}$ in Logistic symbiotic evolution model to define each development phase of producer services and manufacturing, which is described in table 2.

Table 2. Divided stages of development of producer services and manufacturing.

\begin{tabular}{|c|c|c|c|c|}
\hline & Infancy & Growth & Maturity & $\begin{array}{l}\text { Integration } \\
\text { period }\end{array}$ \\
\hline $\mathrm{N}$ & Small & Medium & Large & Large \\
\hline $\mathrm{N} / \mathrm{N}_{\mathrm{m}}$ & $\begin{array}{l}0<N / N_{m}<20 \\
\%\end{array}$ & $\begin{array}{l}20 \%<N / N_{m}<60 \\
\%\end{array}$ & $\begin{array}{l}60 \%<N / N_{m}< \\
90 \%\end{array}$ & $90 \%<N / N_{m}$ \\
\hline $\mathrm{r}$ & Fast & Faster & Low & Lower \\
\hline $\begin{array}{l}\text { Symbiotic } \\
\text { mode }\end{array}$ & $\begin{array}{l}\text { Parasitism } \\
\text { partial }\end{array}$ & $\begin{array}{l}\text { Asymmetrical } \\
\text { mutualism }\end{array}$ & $\begin{array}{l}\text { Asymmetrical } \\
\text { mutualism, } \\
\text { symmetrical } \\
\text { mutualism }\end{array}$ & $\begin{array}{l}\text { Symmetrical } \\
\text { mutualism }\end{array}$ \\
\hline
\end{tabular}

Infancy $\left(T_{0}-T_{1}\right)$ : When $0<N / N_{m}<20 \%$, producer services and manufacturing are at its infancy stage. Most of producer services in manufacturing industry are internalized within the enterprise. With the development of the manufacturing, service function of producer services become diverse and the enterprises which need service also become various. More and more attention has been paid to the producer services now. Productive enterprises begin independently to provide service for manufacturing industry and manufacturing industry, start to seek more producer services. However, the whole structure of the interactive organization is still loose.

Growth stage $\left(T_{1}-T_{2}\right)$ : When $20 \%<N / N_{m}<60 \%$, producer services and manufacturing are at its growth stage. At this stage, the external producer services market has grown up gradually and producer service gets a stable development. In addition, the cluster phenomenon begin to appear, such as all kinds of large comprehensive productive enterprises or enterprise clusters. The manufacturing and service activities within the manufacturing are externalized and productive service sector has been separated from the manufacturing industry to become an enterprise which is self-managed. What's more a stable organization develops from interaction of the manufacturing industry and productive service sector. The cooperation of the manufacturing industry and productive service enterprise is stable and promote each other.

Maturity $\left(T_{2}-T_{3}\right)$ : When $60 \%<N / N_{m}<90 \%$, producer services and manufacturing are at maturity stage. At this stage, the proportion and role of the producer services in manufacturing industry is increasing gradually. A new tight industrial system develops from the interaction of producer services in manufacturing industry. Producer services can provide more professional service, including not only standardized service but also customized and innovative activities. A good resource sharing mechanism has been formed within producer services industry. Productive service function system has been developed in the industry chain of manufacturing industry and conducts the full-scale penetration to the study before production of manufacturing, designs of the mid-term production and information feedback of later production.

Integration period $\left(T_{3}-T_{m}\right)$ : When $90 \%<N / N_{m}$, producer services and manufacturing are at integration period. The border between producer services and manufacturing is obscure and there is a tendency of integration. Indications of the integration of producer services and manufacturing are that investment of intermediary service increases largely and manufacturing industry servicing occurs. This is the advanced stage of symbiotic interaction of two industries and reflects the evolution tendency of future industry.

\section{Conclusion}

From the perspective of symbiosis theory, this paper analyzed the interaction symbiotic modes of the produce services and manufacturing and the following conclusions are given.

(1)The symbiosis unit of producer services and the manufacturing includes the symbiotic organization mode and symbiotic behavior mode. Symbiosis organization mode reflects the symbiosis interaction mode among symbiotic unit, and symbiotic behavior mode reveals the behavioral categories and the benefits distribution of interaction among the units of the symbiotic system.

(2)Symbiotic organization mode includes point symbiosis, batch symbiosis, continuous symbiosis and integration symbiosis. Symbiotic behavior mode includes parasitic symbiosis, partial symbiosis, asymmetric mutualism symbiosis and symmetric mutualism symbiosis.

(3)Symbiosis development stages of producer services and manufacturing is divided into the infancy stage, growth stage, maturity stage and integration stage. The population density and the ratio of the maximum capacity of the environment based on Logistic symbiotic evolutionary model is applied to define the current development stage of producer services and manufacturing.

(4)In the initial budding stage of producer services and manufacturing, symbiotic companies begin to gradually establish a symbiotic relationship, generally producer services parasites in the manufacturing sector. The main symbiosis modes includes point \& parasitic symbiosis, point \& partial symbiosis, batch \& parasitic symbiosis, batch \& partial symbiosis, batch \& asymmetric mutualism symbiosis and continuous \& asymmetric mutualism symbiosis, and then gradually evolves to continuous and asymmetric mutualism symbiosis.

(5)In the growth stage of the producer services and manufacturing, the symbiotic interface among enterprises gradually expands and the symbiosis mode includes batch \& asymmetric mutualism symbiosis, continuous \& asymmetric mutualism symbiosis and continuous \& symmetric mutualism symbiosis. In this stage, producer services and manufacturing develop rapidly.

(6)In the mature stage, the symbiotic interface among 
enterprises is also more diverse, the symbiosis relationship includes continuous \& symmetric mutualism symbiosis, integration \& symmetric mutualism symbiosis, which forms a more stable symbiotic relationship. In the integration stage, the integration \& symmetric mutualism symbiosis is the only symmetric mode.

(7)Development of producer services and manufacturing can be divided into four phases which are infancy, growth, maturity and integration period. Although there are many factors determining the development phase of producer services and manufacturing, this paper uses the ratio of population density and maximum environmental capacity in Logistic symbiotic evolution model to define each development phase of producer services and manufacturing.

\section{Acknowledgements}

The author is grateful for the support of Humanity and Social Science Youth foundation of Ministry of Education of China (14YJC790093).

\section{References}

[1] G. Eason, B. Noble, and I. N. Sneddon, "On certain integrals of Lipschitz-Hankel type involving products of Bessel functions," Phil. Trans. Roy. Soc. London, vol. A247, pp. 529-551.

[2] Huang Qunhui, Li Xiaohua, "Chinese industrial development assessment and the 13th Five-Years" strategy," China Industrial Economy, 2015 (9): 5-20.
[3] Du Zhuying, He Laignag, "Manufacturing and producer services symbiotic behavior selection mechanism analysis," Modern Commerce, 2007, (17): 21-22.

[4] Nie Na, Wang Wupeng, Zhou Jing, "Symbiotic relationship between manufacturing companies and logistics service enterprises," Academic Journal of Southeast University (Natural Sciences), 2007: 409-412.

[5] Xu Xuejun, Feng Jilong, and He Laiang, "Manufacturing and producer services symbiosis mode based on transaction cost," Science and Technology Management Research, 2007: (9): 171-181.

[6] $\mathrm{Hu}$ Xiaopeng, Li Qingke, "Symbiotic relationship between producer services and manufacturing-- dynamic comparison with Jiangsu, Zhejiang, Shanghai based on input-output table," Journal of Quantitative \& Technical Economics, 2009, (2): 33-46.

[7] Liu Hao and Yuan Yijun, "Symbiotic behavior patterns producer services and manufacturing in China," Finance and Trade Research, 2010, 3: 54-59.

[8] Liu Junyue, Li Junfeng and Zhong Sheng, "Research about symbiotic relationship between producer services and manufacturing ---- analysis based on coupling coordination degree of 31 provinces and cities in China," Hunan University of Science and Technology (Social Science Edition), 2013 (16 ): 111-116.

[9] Miao Lindong and Pan Wenqing, "Comparison with symbiotic relationship of three major growth poles between producer services and manufacturing in China," Technical Economics, 2014 (33): 36-43.

[10] Tien, James M., "Manufacturing and services: From mass production to mass customization," Journal of Systems Science and Systems Engineering, 2011, 20 (2): 129-154. 